\title{
ANALISIS PENDAPATAN USAHATANI PEMBIBITAN TANAMAN SAYURAN DI JAMAAH TANI NURSERY
}

\author{
${ }^{1}$ Nina Lisanty, ${ }^{2}$ Wiwiek Andajani, ${ }^{3}$ Tutut Dwi Soetiknjo \\ ${ }^{1,2,3}$ Fakultas Pertanian, Universitas Kadiri \\ ${ }^{1,2,3}$ Kota Kediri, Indonesia \\ E-mail: ${ }^{1}$ lisantynina@unik-kediri.ac.id, ${ }^{2}$ wiwiekand@unik-kediri.ac.id, \\ 3ututdwisoetiknjo@unik-kediri.ac.id
}

\begin{abstract}
A vegetable nursery farm located in Tegalan Village, Kandat District, Kediri Regency, named Jamaah Tani Nursery is a successful pioneer farming of vegetable nursery in Kediri and surrounded regencies. In recent years, the farm was expanded to Blitar and Tulungagung Regencies. Vegetables produced in the nursery consisted of chilli, mustard, eggplant, and others. The research was conducted on this farm to determine which vegetable nursery gave the highest profit. Another objective of the study was to calculate the break-even point (BEP) production and price for each vegetable seed in three locations of the farm (Kediri-Blitar-Tulungagung). This research employed observation and interviews methods on the performance of the farm and the farmer, as the owner of the nursery farm. Based on the results of the research, it was found that the highest overall income was obtained by farmers in the vegetable crop of chilli seeds. Meanwhile, the BEP production in Kediri Regency for mustard seeds was 1,442 polybags, 1,106 polybags for chilli seeds, and 1,447 polybags for eggplant seeds with a price BEP of Rp96.15 (mustard seeds), Rp96.70 (chilli seeds), and Rp144.73 (eggplant seeds). Whereas for BEP production in Blitar Regency for mustard seedlings were 1,710 polybags, 1,150 polybags for chilli seeds, and 1,297 polybags eggplant seeds. The production BEP for mustard seed production in Tulungagung Regency was 1,643 polybags, 1,117 polybags for chilli seeds, and 1,247 polybags for eggplant seeds with BEP prices for mustard, chilli and eggplant seeds were $R p 123.23$, Rp167.48, and Rp124.73 respectively.
\end{abstract}

Keyword: income, farming, nursery, vegetable, BEP

\section{PENDAHULUAN}

Gemah ripah loh jinawi, ungkapan yang sering kali disematkan untuk Indonesia. Kata tersebut mempunyai arti yaitu kekayaan alam yang berlimpah. Indonesia merupakan negara agraris yang kaya akan ragam bahan pangan hayati. Didukung banyaknya sumberdaya manusia, Badan Pusat Statistik (2020) mencatat bahwa 38,23 juta orang penduduk Indonesia bekerja di sektor pertanian atau sebesar 29,76 persen dari 128,45 juta orang penduduk bekerja. Hal ini wajar mengingat tingginya kebutuhan pangan dan permintaan akan produk pertanian sepanjang waktu.

Salah satu komoditi pertanian yang permintaannya cukup tinggi adalah komoditi hortikultur yaitu sayuran. Sayuran termasuk komoditi multi manfaat di antaranya sebagai sumber pangan dan gizi, kontributor pendapatan rumah tangga, dan turut berkontribusi dalam pennambah devisa negara. Komoditas hortikultura sayuran Indonesia cukup melimpah, beragam, dan menjadi unggulan untuk produk ekspor. Bawang merah (Lisanty 
et al., 2020), kubis, jamur, kentang, cabai (Purba et al., 2020), adalah di antara komoditi sayuran unggulan Indonesia (Badan Pusat Statistik, 2018).

Suatu usahatani pembibitan di Desa Tegalan Kecamatan Kandat Kabupaten Kediri yang bernama Jamaah Tani Nursery membudidayakan pembibitan beragam jenis sayuran. Usahatani ini termasuk perintis dan pelopor usahatani pembibitan yang sejenis di wilayahnya. Fokusnya adalah memproduksi bibit tanaman sayuran dan buah, menghimpun hasil produksi pembibitan dari petani yang tergabung dalam kelompok tani sekitar lokasi usaha tersebut, dan memperjualbelikan bibit tanaman baik secara ecer maupun grosir (dalam partai besar). Menariknya, usahatani ini juga melebarkan sayapnya di daerah lain di Karesidenan Kediri, yaitu Blitar dan Tulungagung dengan menjaring petani dan kelompok tani hortikultura sayuran di wilayah tersebut. Jamaah Tani Nursery mempunyai lahan untuk budidaya pembibitan sayuran sebagai strategi pengembangan agribisnis dan menambah biaya pendapatan untuk setiap petani pembibitan. Besar kecilnya pendapatan yang diperoleh petani secara nyata berpengaruh terhadap motivasi petani untuk bertani. Semakin banyak pendapatan yang diperoleh petani, semakin aktif dan antusias mereka dalam kegiatan pertanian.

Penelitian dilakukan dengan fokus kepada tiga komoditi utama pada usahatani Jamaah Tani Nursery, yaitu cabai, sawi, dan terong. Dari ketiga sayuran tersebut, peneliti ingin mengetahui komoditi sayuran manakah yang berkontribusi paling tinggi terhadap pendapatan petani. Adapun hasil dari penelitian ini sesuai harapannya adalah agar dapat menjadi bahan pertimbangan petani pembibitan tanaman sayuran di Jamaah Tani Nursery untuk memperluas usahanya dan memperbanyak jumlah sayuran yang paling diminati dan memiliki keuntungan yang lebih besar. Selanjutnya, penelitian dilakukan untuk menganalisis titik impas (break event point) produksi dan harga dari masing-masing komoditi di setiap lokasi usahatani Jamaah Tani Nursery. Hal ini dilakukan dengan harapan bahwa tidak ada kerugian bagi petani dalam melakukan usahatani mengingat kemampuan dan pengetahuan finansial dan analisis ekonomi petani masih sangat minim.

\section{METODE PENELITIAN}

Lokasi dan Waktu Penelitian. Penelitian dilakukan pada usahatani Jamaah Tani Nursery yang merupakan usahatani pembibitan sayuran pelopor dan cukup besar di Kabupaten Kediri dan telah juga menjangkau wilayah lain di Blitar dan Tulungagung. Penelitian dimulai pada Desember 2020 hingga Februari 2021. Kemudian pengolahan dan analisis data dilakukan hingga bulan Maret 2021.

Responden dan Pengumpulan Data. Objek penelitian adalah petani di Jamaah Tani Nursery. Observasi dilakukan dengan secara langsung mengamati karakteristik responden dan kondisi usahatani kemudian mengajukan daftar pertanyaan kepada pemilik Jamaah Tani Nursery dan 19 orang pekerja tetapnya.

Analisis Data. Analisis biaya dan pendapatan petani menggunakan data yang diperoleh selama proses penelitian berlangsung yang kemudian diolah dengan program MS. Office Excel untuk dianalisis lebih lanjut. Analisis biaya dan pendapatan bertujuan mengukur dan mengetahui besaran biaya usahatani, penerimaan, pendapatan dan BEP petani bibit sayuran Jamaah Tani Nursery. Hipotesis penelitian diuji dengan uji statistika parametrik Anova atau analysis of variance yang bertujuan untuk menguji hipotesis penelitian dan melihat adanya perbedaan rata-rata antar kelompok. Terakhir, dilakukan uji BNT atau yang lebih dikenal sebagai uji LSD (least significance different) adalah 
metode yang menjadi penentuan adanya perbedaan rata-rata antar kelompok secara stastistik.

\section{HASIL DAN PEMBAHASAN}

Gambaran Umum Usahatani Jamaah Tani Nursery. Usahatani pembibitan sayuran Jamaah Tani Nursery merupakan usaha di bidang pertanian, khususnya pembibitan berbagai komoditi sayuran seperti sawi, cabai, terong, seledri, bawang pre, tomat, kembang kol, kubis, strawberi, dan sebagainya. Usahatani ini pertama kali didirikan di Desa Tegalan Kecamatan Kandat Kabupaten Kediri dan hingga saat ini telah berjalan selama lebih kurang 9 tahun sejak 2012 dengan jumlah karyawan 4 orang di bagian pengolahan lahan, 6 orang di bagian pembibitan, 6 orang bagian pemeliharaan, dan 3 orang bagian transportasi. Sejak berdirinya hingga saat ini usaha pembibitan sayuran terus mengalami peningkatan produksi bibit meskipun sempat jatuh bangun. Sebelum usaha pembibitan ini dibangun, pemilik mengusahakan ternak sapi dan kambing yang pada akhirnya mengalami kegagalan. Pengelolaan dalam usahatani ini dikelola sendiri oleh pemilik, Bapak M. Munirkhan dibantu oleh istrinya. Seiring perjalanan waktu, konsumen Jamaah Tani Nursery semakin banyak sehingga menginisiasi pemilik untuk mulai membuka cabang di Blitar dan Tulungagung dengan lahan milik sendiri. Luas lahan yang diolah untuk usahatani pembibitan tanaman sayuran di ketiga lokasi masing-masing sebesar $10.000 \mathrm{~m}$. Pemilik mempekerjakan para tetangga di lingkungan rumahnya sebagai pekerja di Jamaah Tani Nursery dengan harapan dapat membantu menambah biaya hidup tetangga sekitar dan mengurangi pengangguran di lingkungannya. Hal ini sejalan dengan kegiatan gotong royong penanaman tanaman sayuran di Sampang, Jawa Timur (Kiptiyah et al., 2020).

Pemilik berusia 46 tahun dengan tingkat pendidikan terakhir adalah Sekolah Dasar (SD). Usahatani pembibitan sayuran bukanlah merupakan pengalaman baru bagi pemilik. Hal ini dapat dilihat dari pengalaman bertani pemiliki, keluarganya, dan para pekerja yang telah menggeluti usaha bercocok tanam tanaman sayuran yaitu selama lebih dari 15 tahun. Meski memiliki tingkat pendidikan yang tergolong rendah, usia yang masih terbilang muda mempengaruhi kemampuan fisik dan berpikir dari pemilik dalam pengembangan usahataninya. Dengan alasan keterbatasan modal, pemilik mengungkapkan kesulitannya untuk mengadopsi inovasi-inovasi baru dalam usahatani pembibitan ke dalam usahanya, seperti teknologi otomatisasi pemanfaatan air (Saparso et al., 2016). Oleh karena itu, usahatani pembibitan tanaman sayuran Jamaah Tani Nursery masih bersifat tradisional, dan dilakukan bersebelahan dengan pekarangan rumah pemilik.

Kegiatan produksi usahatani pembibitan tanaman sayuran dimulai dengan pengolahan lahan. Pertama, gunakan cangkul untuk menggali tanah sedalam 20 hingga 30 $\mathrm{cm}$ untuk mengolah tanah menjadi tanah gembur. Selanjutnya, petani membuat bedengan yang membujur dari barat ke timur dengan tujuan agar tanaman memperoleh pencahayaan yang cukup (Edi \& Bobihoe, 2010). Setelah membuat bedengan, petani mencampur tanah dan media tanam lainnya dengan pupuk dan dimasukan ke dalam polybag polos ukuran kecil. Sebelum disemai, benih direndam selama lebih kurang 2 jam kemudian dikeringkan. Setelah itu, dimasukan ke polybag yang sudah diisi media tanam dan polybag ditata di bedengan. Petani menyiram tanaman setiap hari hingga benih sayuran tumbuh normal, lalu mengulangi penyiraman sesuai kebutuhan. Jika tanaman mati, segera disulam. Secara teori, penyulaman harus diselesaikan 10 hari sebelum benih membesar. (Rahmawati \& Anwar, 2020). Penyiangan dilakukan tergantung kepada keberadaan gulma. 
Analisis Pendapatan Usahatani Pembibitan Tanaman Sayuran. Jika selisih pendapatan dan pengeluaran positif, pertanian dikatakan menguntungkan. Semakin besar keseimbangan pendapatan dan pengeluaran, semakin tinggi pula keuntungan usahataninya. Analisis pendapatan merupakan tema utama penelitian ini, sejauh mana pertanian pembibitan tanaman sayuran dapat memperoleh manfaat dari biaya pertanian. Perhitungan pendapatan tentunya dimulai dengan menghitung semua biaya yang dikeluarkan petani untuk usahataninya.

Biaya produksi merupakan keseluruhan pengeluaran dana selama proses produksi berlangsung untuk menunjang kegiatan produksi. Biaya produksi pada usahatani pembibitan tanaman sayuran Jamaah Tani Nursery terdiri dari biaya bibit, pupuk, polybag, tenaga kerja, dan biaya penyusutan alat. Jumlah input produksi dan harga input tersebut mempengaruhi besaran biaya produksi pembibitan. Biaya produksi usahatani pembibitan sayuran secara rata-rata ditunjukkan oleh Tabel 1.

Tabel 1. Biaya produksi rata-rata pembibitan tanaman sayuran per sekali produksi per komoditi tanaman sawi, cabai, dan terong

\begin{tabular}{lr}
\hline \multicolumn{1}{c}{ Jenis biaya } & Jumlah (Rupiah) \\
\hline Biaya sarana produksi & 579.000 \\
Biaya tenaga kerja & 530.000 \\
Biaya peralatan & 7.910 \\
\hline \multicolumn{1}{c}{ Total } & 1.118 .000 \\
\hline
\end{tabular}

Biaya sarana produksi untuk satu kali produksi terdiri atas pembelian benih tanaman (sawi, cabai, dan terong) dan polybag. Untuk media tanam, petani meracik sendiri dengan penggunaan beberapa jenis media tanam (Hadiyanti et al., 2020; Ningsih, 2014). Untuk pupuknya, petani memakai pupuk kandang dari ternaknya sendiri (Junaidi \& Rahardjo, 2021). Sedangkan jumlah hari kerja yang dilakukan dan rerata enam jam waktu kerja per hari per orang menjadi dasar besaran biaya tenaga kerja. Jumlah tenaga kerja yang diberdayakan sekitar 2 hingga 3 orang yang berasal dari lingkungan tempat tinggal. Oleh karena itu, biaya yang dikeluarkan untuk tenaga kerja sebesar Rp530.000. Sedangkan biaya peralatan adalah biaya penyusutan peralatan usahatani yang digunakan yang terdiri dari cangkul, gembor, alat semprot, dan sabit sebesar Rp7.910. Total biaya produksi untuk usahatani pembibitan per produksi adalah sebesar Rp1.118.000.

Penerimaan rata-rata petani adalah sebesar Rp4.650.000 per sekali produksi yang diperoleh dari harga jual untuk masing-masing bibit sayuran sawi, cabai, dan terong per polybag yaitu berkisar antar Rp150 hingga Rp300. Petani menetapkan harga yang berbeda-beda untuk penjualan di Kediri, Blitar, maupun Tulungagung. Lebih rinci mengenai penerimaan dituangkan dalam Tabel 2. 
Tabel 2. Rata-rata penerimaan usahatani pembibitan sayuran per satu kali produksi berdasarkan lokasi usahatani

\begin{tabular}{lccccccccc}
\hline \multirow{2}{*}{ Daerah } & \multicolumn{3}{c}{ Produksi bibit } & \multicolumn{3}{c}{ Harga jual } & \multicolumn{3}{c}{ Penerimaan } \\
\cline { 2 - 10 } & sawi & cabai & terong & sawi & cabai & terong & sawi & cabai & terong \\
\hline \multirow{2}{*}{ Kediri } & 3000 & 3000 & 2000 & 200 & 350 & 200 & 600.000 & 1.050 .000 & 400.000 \\
Blitar & 2000 & 2000 & 2000 & 150 & 300 & 200 & 300.000 & 600.000 & 400.000 \\
\multirow{2}{*}{ Tulungagung } & 2000 & 2000 & 2000 & 150 & 300 & 200 & 300.000 & 600.000 & 400.000 \\
\hline & & & & & & Total & 1.200 .000 & 2.250 .000 & 1.200 .000 \\
\hline
\end{tabular}

Selanjutnya, berdasarkan informasi biaya dan penerimaan, pendapatan petani dapat ditentukan. Pendapatan usahatani per satu kali produksi untuk tanaman sawi di Kediri diketahui sebesar Rp332.590, di Blitar sebesar Rp64.590, dan di Tulungagung sebesar Rp74.590 dengan total pendapatan bibit sawi adalah Rp471.771. Pendapatan usahatani untuk bibit cabai di Kediri adalah sebesar Rp692.000, di Blitar Rp276.090, dan di Tulungagung sebesar Rp286.090 dengan total pendapatan bibit cabai sebesar Rp1.254.181. Sementara itu, pendapatan usahatani bibit terong di Kediri, Blitar, dan Tulungagung, secara berturut-turut adalah sebesar Rp131.590, Rp161.590, dan Rp171.590 dengan total pendapatan sebesar Rp464.771. Rata-rata total biaya dan pendapatan usahatani pembibitan sayuran Jamaah Tani Nursery ditampilkan pada Tabel 3.

Tabel 3. Rata-rata total biaya dan pendapatan usahatani pembibitan sayuran Jamaah Tani Nursery per satu kali produksi tanaman sawi, cabai, dan terong

\begin{tabular}{|c|c|c|c|c|c|}
\hline \multicolumn{3}{|c|}{ Total Biaya (Rp) } & \multicolumn{3}{|c|}{ Pendapatan (Rp) } \\
\hline Sawi & Cabe & Terong & Sawi & Cabe & Terong \\
\hline 267.410 & 358.000 & 268.410 & 332.590 & 692.000 & 131.590 \\
\hline 235.410 & 323.910 & 238.410 & 64.590 & 276.090 & 161.590 \\
\hline 225.410 & 313.910 & 228.410 & 74.590 & 286.090 & 171.590 \\
\hline \multicolumn{3}{|c|}{ Jumlah Pendapatan } & 471.771 & 1.254 .181 & 464.771 \\
\hline
\end{tabular}

Break Event Point (Titik impas) Produksi dan Harga. Penentuan titik impas (BEP) produksi dapat diketahui dengan biaya produksi dan pendapatan, sedangkan untuk penentuan harga minimum, dapat diketahui dari total biaya pokok dan harga jual setiap komoditas sayuran. Secara rinci, hal ini digambarkan dalam Tabel 4. 
Tabel 4. Titik impas usahatani pembibitan tanaman sayuran Jamaah Tani Nursery

\begin{tabular}{|l|c|r|r|r|r|}
\hline \multicolumn{7}{|c|}{ Bibit Sawi } \\
\hline \multicolumn{1}{|c|}{ Wilayah } & Biaya & Produksi & Harga & BEP produksi & BEP harga \\
\hline Kediri & 308.452 & 3.000 & 200 & 1.542 & 102,82 \\
\hline Blitar & 275.452 & 2.000 & 150 & 1.836 & 137,73 \\
\hline Tulungagung & 265.452 & 2.000 & 150 & 1.769 & 132,73 \\
\hline \multicolumn{7}{|c|}{ Bibit Cabai } \\
\hline Wilayah & Biaya & Produksi & Harga & BEP produksi & BEP harga \\
\hline Kediri & 405.952 & 4.000 & 350 & 1.160 & 101,49 \\
\hline Blitar & 363.952 & 2.000 & 300 & 1.213 & 181,98 \\
\hline Tulungagung & 353.952 & 2.000 & 300 & 1.180 & 176,98 \\
\hline \multicolumn{7}{|c|}{ Bibit Terong } \\
\hline Wilayah & Biaya & Produksi & Harga & BEP produksi & BEP harga \\
\hline Kediri & 308.452 & 2.000 & 200 & 1.542 & 154,23 \\
\hline Blitar & 278.452 & 2.000 & 200 & 1.392 & 139,23 \\
\hline Tulungagung & 268.452 & 2.000 & 200 & 1.342 & 134,23 \\
\hline
\end{tabular}

Tabel di atas menunjukan bahwa nilai BEP rata-rata yang diperoleh petani pembibitan tanaman sayuran adalah sebagai berikut: BEP produksi bibit sawi di Kediri adalah 1.542 polybag, di Blitar 1.836 polybag, dan di Tulunggagung 1.769 polybag, sedangkan BEP harga untuk bibit sawi di Kediri sebesar Rp102.817, di Blitar Rp137.726, dan di Tulungagung sebesar Rp132.726. BEP produksi bibit cabai di Kediri adalah sebesar 1.159 polybag, di Blitar sebanyak 1.213 polybag, sedangkan di Tulungaggung sebanyak 1.179 polybag, dan untuk BEP harga bibit cabai di Kediri, Blitar, dan Tulungagung berturut-turut adalah sebesar Rp154.226, Rp139.226, dan Rp134.226. Untuk BEP produksi bibit terong di Kediri sebanyak 1.542 polybag, di Blitar 1.359 polybag, dan di Tulungaggung 1.342 polybag. Untuk BEP harga bibit terong di Kediri, Blitar, dan Tulungagung secara berurutan adalah sebesar Rp154.226, Rp139.226, dan Rp134.226.

Pengujian Statistika. Pengujian Anova dilakukan dan memperoleh hasil Fhitung > Ftabel maka disimpulkan bahwa benar ada perbedaan pendapatan petani untuk usahatani bibit tanaman sayuran sawi, cabai, dan terong. Kemudian, analisis dilanjutkan dengan uji BNT. Adapun interpretasi dari hasil uji BNT adalah bahwa tanaman cabai memberikan pendapatan yang paling tinggi dibandingkan tanaman sawi dan terong bagi petani.

\section{KESIMPULAN}

Usahatani pembibitan tanaman sayuran cabai diketahui memberikan keuntungan paling tinggi dibandingkan jenis komoditi tanaman sayuran lainnya pada Jamaah Tani Nursery. Sementara itu, berdasarkan perhitungan titik impas produksi maupun harga diketahui bahwa ketiga komoditi sayuran telah melampaui titik impas dari segi produksi maupun harga jual. Hal ini berarti petani dan pemilik Jamaah Tani Nursery sudah melakukan usahatani yang menguntungkan. Pengembangan agribisnis usahatani pembibitan perlu untuk dilakukan agar usahatani dapat mencapai keuntungan yang lebih besar dan menyerap lebih banyak tenaga kerja. 


\section{DAFTAR PUSTAKA}

Badan Pusat Statistik. (2018). Statistik Tanaman Sayuran dan Buah-Buahan Semusim Indonesia 2018. Subdirektorat Statistika Hortikultura, 101. https://www.bps.go.id/publication/2019/10/07/9c5dede09c805bc38302ea1c/statisti k-tanaman-sayuran-dan-buah---buahan-semusim-indonesia-2018.html

Badan Pusat Statistik. (2020). Booklet Survei Angkatan Kerja Nasional Agustus 2020. In Subdirektorat Statistik Ketenagakerjaan (Ed.), Booklet Sakernas. Badan Pusat Statistik.

Edi, S., \& Bobihoe, J. (2010). Buklet: Budidaya Tanaman Sayuran (Firdaus (ed.)). Balai Pengkajian Teknologi Pertanian (BPTP) Jambi Alamat. http://dergipark.gov.tr/cumusosbil/issue/4345/59412

Hadiyanti, N., Lisanty, N., \& Aji, S. B. (2020). KAJIAN PRODUKSI JAMUR KUPING (Auricularia auriculajudae) PADA BERBAGAI KOMPOSISI MEDIA TANAM. Jurnal Agrinika: Jurnal Agroteknologi Dan Agribisnis, 4(1), 1-14. https://doi.org/10.30737/agrinika.v4i1.794

Junaidi, J., \& Rahardjo, D. (2021). Upaya Optimalisasi Hasil Panen Padi Menggunakan Berbagai Model Jarak Tanam Dan Dosis Pupuk Kandang. Jurnal Agrinika : Jurnal Agroteknologi Dan Agribisnis, $\quad 5(1), \quad 84$. https://doi.org/10.30737/agrinika.v5i1.1554

Kiptiyah, M., Athena, T., Hafidz, M., Lis, I. M., Soleh, B., \& Mutmainnah, S. (2020). RUSA (RUMAH SAYUR) SEBAGAI PEMBENTUKAN PEMUDA BERKARAKTER GOTONG ROYONG DI KECAMATAN BANYUSOKAH SAMPANG. Abdiku, 3(2), 64-71.

Lisanty, N., Sutiknjo, T. D., Artini, W., \& Pamujiati, A. D. (2020). Saluran Pemasaran Bawang Merah di Desa Sentra Produksi Kabupaten Nganjuk Provinsi Jawa Timur. Jimanggis, 1(2), 69-86.

Ningsih, E. P. (2014). RESPON PENGGUNAAN MEDIA TANAM PADA PEMBIBITAN SELADA (Lactuca sativa L.) (Response. Jurnal Ilmu Pertanian Dan Perikanan, 3(2), 111-116.

Purba, Y. Z. W., Novitarini, E., \& Fahrurozi, M. (2020). Analisis Pemasaran Usahatani Cabai Merah Keriting Di Kelurahan Sei Selincah Kecamatan Kalidoni Palembang. Agrinika, 4(2), 167-185. https://doi.org/10.51517/ags.v2i2.230

Rahmawati, D., \& Anwar, R. B. (2020). Peningkatan kualitas bibit sayur pada petani bibit sayur di desa siraman. Seminar Nasional Penelitian Dan Pengabdian Kepada Masyarakat Tahun 2020, 2, 447-451.

Saparso, Sudarmaji, A., \& Ramadhani, Y. (2016). Penerapan Teknologi Otomatisasi Pemanfaatan Air dalam Peningkatan Kapasitas Agribisnis Pembibitan Tanaman Sayuran di Wilayah Pesisir Adipala, Cilacap, Jawa Tengah. Pengembangan Sumber Daya Pedesaan Dan Kearifan Lokal Berkelanjutan VI, November. 
p-ISSN: 1978-5259 e-ISSN: 2527-3345

Copyright@UNISBA Blitar, http://ejournal.unisbablitar.ac.id/index.php/viabel

Nina Lisanty, Wiwiek Andajani \& Tutut Dwi Soetiknjo, 2021. Analisis Pendapatan Usahatani

Pembibitan Tanaman Sayuran Di Jamaah Tani Nursery.

Journal Viabel Pertanian. (2021), 15(1) 58-64 